Article type: Original manuscript

Corresponding author:

Rebecca Randell, School of Healthcare, University of Leeds, Leeds LS2 9JT, UK

Email: r.randell@leeds.ac.uk

\title{
How do team experience and relationships shape new divisions of labour in robot-assisted surgery? A realist investigation
}

\author{
Rebecca Randell ${ }^{1}$. Joanne Greenhalgh ${ }^{1}$. Jon Hindmarsh ${ }^{2}$. \\ Stephanie Honey ${ }^{1}$. Alan Pearman ${ }^{1}$. Natasha Alvarado ${ }^{1}$. Dawn \\ Dowding $^{3}$ \\ ${ }^{1}$ University of Leeds, Leeds, UK \\ ${ }^{2}$ King's College London, London, UK \\ ${ }^{3}$ University of Manchester, Manchester, UK

\section{Abstract}

Safe and successful surgery depends on effective teamwork between professional groups, each playing their part in a complex division of labour. This paper reports the first empirical examination of how introduction of robot-assisted surgery changes the division of labour within surgical teams and impacts on teamwork and patient safety. Data collection and analysis was informed by realist principles. Interviews were conducted with surgical teams across nine UK hospitals and, in a multi-site case study across four hospitals, data were collected using a range of methods, including ethnographic observation, video recording, and semi-structured interviews. Our findings reveal that as the robot enables the surgeon to do more, the surgical assistant's role becomes less clearly defined. Robot-assisted surgery also introduces new tasks for the surgical assistant and scrub practitioner, in terms of communicating information to the surgeon. However, the use of robot-assisted surgery does not redistribute work in a uniform way; contextual factors of individual experience and team relationships shape changes to the division of labour. For instance, in some situations scrub practitioners take on the role of supporting inexperienced surgical assistants. These changes in the division of labour do not persist when team members return to operations that are not robot-assisted. This study contributes to wider literature on divisions of labour in healthcare and how this is impacted by the introduction of new technologies. In particular, we emphasise the need to pay attention to often neglected micro level contextual factors. This can highlight behaviours that can be promoted to benefit patient care.

Keywords 
Professional boundaries; Interprofessional working; Ethnography; Negotiated order; Robot-assisted surgery; Realist methods; Division of labour.

\section{Introduction}

Safe, successful surgery depends on effective teamwork between professional groups, each playing their part in a complex division of labour (Sanchez Svensson et al., 2007). However, opportunities for effective teamwork are complicated by the fact that the operating theatre is a site of regular and significant change. For instance, new technologies are often introduced into surgical practice (Prentice, 2013). These facilitate radical changes in surgical techniques, such as the introduction of laparoscopic surgery, which impact on the division of labour (Edmondson et al., 2001). Furthermore, surgery has seen a re-ordering of professional boundaries; scrub practitioner, circulating practitioner, and anaesthetic assistant roles, traditionally the preserve of theatre nurses, may now be taken on by operating department practitioners (ODPs) (Timmons and Tanner, 2004; Timmons, 2011); first assistant training, now available to theatre nurses and ODPs, provides access to the previously inaccessible role of surgical assistant. Studies of the division of labour in the operating theatre (OT) have tended to focus on divisions between consultant surgeons and trainees (Bezemer et al., 2012; Bezemer et al., 2014; Bosk, 2003), with scant attention paid to the wider team.

An intriguing and contemporary case to explore these issues is provided by the introduction of robot-assisted surgery (RAS), which has grown rapidly in Europe and the United States (Abrishami et al., 2014). RAS was developed to reduce the technical challenges of laparoscopic surgery. The da Vinci® robot, developed by Intuitive Surgical, is a master-slave (or console-manipulator) system, where the surgeon sits at a console to control the robot arms. The robot provides a magnified, three dimensional image of the surgical site, tremor elimination, motion scaling, and instruments which increase freedom of movement. Instrument handling is claimed to be intuitive. Together these resources are argued to increase precision. Robot-assisted surgeons can conduct the operation in a way that is impossible in laparoscopic surgery: the surgeon controls the laparoscopic camera, a task previously undertaken by a surgical assistant; retraction can be managed by the surgeon without a surgical assistant's help. Changes of instruments are less frequent, altering the role and workload of the scrub practitioner.

The perception of the surgeon as the centre of surgical 'action' (Prentice, 2013) and surgery's reputation as a 'body-contact sport' (Bosk, 2003; Prentice, 2013) mean moving the surgeon away from the patient represents a significant change in how surgical work is carried out. Indeed, the introduction of RAS can transform the ways in which labour is distributed amongst the team and can change professional jurisdictions. Interestingly, previous studies of RAS have neglected to address these changes, despite the importance of teamwork for patient safety (Greenberg et al., 2007; Hull et al., 2012; Vincent, 2010).

We report the first empirical examination of how a change to the division of labour in the OT is triggered by the introduction of RAS. We pay particular attention to how surgical assistant and scrub practitioner roles are affected and the consequences for teamwork and 
patient safety. To understand negotiation of the division of labour within RAS, and how contextual factors shape that negotiation, we present findings from a realist investigation of the impact of RAS on teamwork in the OT.

First we consider the literature on the division of labour in healthcare, particularly in relation to the introduction of new technologies. We then present the study methods. Findings are organised around two contextual factors at the micro level revealed to be important in influencing the redistribution of work triggered by the introduction of RAS: individual experience and team relationships. We conclude by reflecting on how the findings compare to existing studies of the division of labour in healthcare.

\section{Divisions of labour in healthcare}

The division of labour is one of the most fundamental of all social processes (Hughes, 2008) and has an enduring appeal for social scientists. Negotiated order (Strauss et al., 1963) and boundary theory (Abbott, 1988) are two influential perspectives on divisions of labour in healthcare. Negotiated order posits that internal and external changes impact the social order within a hospital and lead to renegotiation of that social order (Strauss et al., 1963). Negotiations can be triggered in ambiguous or uncertain situations (Hall and Spencer-Hall, 1982). The division of labour, as part of the social order, is accomplished through this process of negotiation. Such negotiations can be general or specific in scope, happen explicitly or implicitly, but are always temporary, the division of labour being an ongoing accomplishment (Strauss et al., 1964). The contextual features of the setting where negotiation happens matter (Maines, 1982; Strauss, 1978). Negotiated order is concerned with negotiation at the micro and meso levels, rather than the negotiation of roles by professional bodies. Thus, features of the negotiation context include organisational hierarchies, local rules and conventions (but which themselves are open to negotiation), and personal relations (Strauss, 1978).

Boundary work - the construction of professional boundaries - helps establish and reproduce professions (Fournier, 2000). Changes to the division of labour challenge these boundaries (Abbott, 1988). Consequently, Fournier (2000) characterises the 'labour of division' as a key process of boundary work. Studies of boundary-blurring in healthcare draw attention to how divisions of labour are socially accomplished in particular situations (Allen, 1997; Liberati, 2017) and how these divisions may result in professional boundaries that conflict with organisational policy and professional bodies' codes of practice (Allen, 1997).

\section{Division of labour in the operating theatre}

The team brought together to perform an operation will typically include: a consultant surgeon; a surgical assistant, who assists the surgeon in carrying out the operation; a scrub practitioner, who ensures the availability and sterility of surgical instruments, passing them to the surgeon as they are needed; a circulating practitioner; an anaesthetist; and an anaesthetic assistant. Studies of the division of labour in surgery have largely focused on surgeons and trainees. Bosk (2003), in his ethnography of American OTs in 
the 1970s, considered the 'tightly controlled, well-supervised' division of technical labour between consultant surgeons and those in training; to minimise technical errors, those in training do not advance to complex tasks until they have demonstrated their competence at simpler tasks. Such divisions of labour endure across time and continents; more recent workplace studies undertaken in the United Kingdom (UK) reveal frequent shifts in the degree of participation of surgical trainees between and within stages of an operation (Bezemer et al., 2012). When a trainee is acting as a 'supervised surgeon', the surgeon may take over momentarily, for reasons of safety or to support the trainee's learning by demonstrating how to undertake a particular task (Bezemer et al., 2014). This division of labour is influenced by the surgeon's knowledge of the trainee and the extent to which they trust the trainee. These studies demonstrate that OT division of labour negotiations shape the training opportunities afforded to trainees.

Another area of focus has been the division of labour between surgeons and anaesthetists. For example, Serra (2010) describes how surgeons and anaesthetists work closely as a unit in liver transplant operations but, even when the same surgeons and anaesthetists are involved, this close collaboration does not occur in other types of operations. Other workplace studies of the OT emphasise how shared knowledge among the team of the expected division of labour is an important resource for supporting coordination; it enables requests that would otherwise seem ambiguous, in terms of content and intended recipient, to be understood so that requests are fulfilled in a timely manner, contributing to safe, successful performance of the operation (Bezemer et al., 2011; Sanchez Svensson et al., 2007).

Finally, others have pointed to how the division of labour is influenced by the hierarchy of the OT. For example, Finn (2008) showed how nurses and ODPs act in accordance with the instructions of surgeons and anaesthetists. It has been argued that there is a tension between the structural inequalities that characterise the division of labour and the requirement for teamwork (Finn, 2008; Finn et al., 2010b). These structural inequalities influence the negotiation context; surgeons' and anaesthetists' privileged position of power and material reward over nurses and ODPs mean they have more power and motivation to reproduce and legitimate, rather than challenge, the existing order (Finn, 2008). However, others argue the hierarchy is fluid rather than rigid (Bezemer et al., 2011) and some studies of surgery support this view (Riley and Manias, 2009; Riley and Manias, 2006).

\section{New technologies and the division of labour}

The studies reviewed above discuss the division of labour within established technologies. In our study of RAS, we also need to understand how the division of labour can be changed or disrupted by introduction of new technologies. A number of empirical studies have explored how introduction of a range of healthcare technologies, including CT scanners (Barley, 1986), pharmacy dispensing robots (Barrett et al., 2012), and electronic patient record systems (Håland, 2012), can trigger a re-negotiation of the division of labour. These studies reveal it is not just the division of tasks that changes but also the division of skills, status, and visibility of work. Similar insights are found in 
studies within surgery. For example, Edmondson et al.'s (2001) study of the introduction of laparoscopic surgery for cardiac operations revealed how it not only changed individual team members' tasks but also blurred role boundaries and impacted the hierarchy within the OT, with the surgeon shifting from 'order giver to a team member in the more interdependent process' (p.691).

The potential for RAS to impact the division of labour has previously been noted. Results from an interview study describe how, as the surgeon is no longer in the sterile field, greater burden falls on the rest of the team to respond in the event of a complication and, as the surgeon is not able to see the patient directly, he/she is more dependent on the rest of the team communicating the status of the patient to maintain situation awareness (Lai and Entin, 2005), while recent research has highlighted the impact on opportunities for training (Beane, In press). Such changes have implications for teamwork, safety, efficiency, and, ultimately, clinical effectiveness. While previous studies recognise that technology influences the division of labour, we consider the micro level factors that mediate that negotiation.

\section{Methods}

Realist enquiry is a theory-driven approach that involves eliciting, testing, and refining stakeholders' theories of how an intervention works (Pawson and Tilley, 1997) and has been used for studying the implementation of a number of complex interventions in healthcare (Marchal et al., 2012; Dalkin et al., 2015; Greenhalgh et al., 2009). We undertook a three phase realist investigation to understand the impact of RAS on teamwork in the OT.

For realists, interventions in and of themselves do not produce impacts. Rather, it is the responses of the intervention recipients to the resources the intervention provides, known as mechanisms, that determine the impact, and such responses are highly influenced by context (Dalkin et al., 2015). A benefit of realist enquiry is the specificity that it offers in terms of understanding the relationship between contexts, mechanisms and impacts, in contrast to more general qualitative approaches. Realist explanations of how interventions lead to particular impacts are expressed as theories in the form of Context Mechanism Outcome (CMO) configurations where $\mathrm{C}+\mathrm{M}=\mathrm{O}$. Consequently, we sought not just to determine the impact of RAS on teamwork but to understand in what ways and why the impact of RAS on teamwork differed according to the context. While the term 'theory' is often used to refer to sociological theories, in realist enquiry the term is simply to refer to practitioners' ideas and thoughts about how an intervention works (Pawson and Tilley, 1997). From a realist standpoint, effective theories typically combine both substantive theory and stakeholders' theories derived from experience.

Phase 1 of the study elicited stakeholders' theories concerning how and in what contexts RAS impacts teamwork through 44 interviews across nine UK hospitals with theatre teams using RAS for colorectal operations. Phase 2 used a multi-site case study to test and refine these theories. In Phase 3, 13 interviews with staff in the case sites and representing other surgical specialties (urology, gynaecology, and upper gastrointestinal 
surgery) were used to assess the extent to which the findings of Phase 2 were theoretically transferrable and to further refine the resulting theories to reflect the experience of a broader range of surgical specialties. In this paper, we present a broader overarching theory that explains how individual experience and team relationships shape the configuration of the division of labour in RAS, drawing predominantly on the findings of Phase 2.

\section{Data collection}

For Phase 2, four hospitals were purposively sampled from the nine hospitals that participated in Phase 1 to maximise rigour in relation to applicability and theoretical transferability. We ensured variation in experience of the surgeon and team with RAS, in terms of the number of years that they had been undertaking RAS, as this was identified as an important contextual factor in the theories to be tested (Table 1). Other contextual factors considered important were which professional group took on the role of surgical assistant in RAS, the nature and extent of training in RAS that had been undertaken by the wider team, including whether they had attended the training provided by Intuitive Surgical as a team, and whether a dedicated team had been established for undertaking RAS. In addition, we ensured the case sites included both large teaching hospitals and district general hospitals. Data were collected using multiple methods, including video recording of operations, ethnographic observation, and semi-structured interviews, to allow development of comprehensive and plausible accounts (full details of methods are available in the published protocol (Randell et al., 2014)).

Table 1: Case site characteristics

\begin{tabular}{|c|l|l|l|l|l|}
\hline Site & $\begin{array}{l}\text { Experience } \\
\text { with RAS }\end{array}$ & $\begin{array}{l}\text { Surgical } \\
\text { assistants }\end{array}$ & $\begin{array}{l}\text { Training for } \\
\text { wider team }\end{array}$ & Team & $\begin{array}{l}\text { Hospital } \\
\text { type }\end{array}$ \\
\hline A & 3 years & Mainly ODPs & $\begin{array}{l}\text { Limited } \\
\text { training }\end{array}$ & $\begin{array}{l}\text { No dedicated } \\
\text { team }\end{array}$ & Teaching \\
\hline B & 4 years & ODPs & Team training & $\begin{array}{l}\text { Tedicated } \\
\text { team initially }\end{array}$ & DGH \\
\hline C & 2 years & $\begin{array}{l}\text { Surgical } \\
\text { trainees }\end{array}$ & $\begin{array}{l}\text { Team training } \\
\text { and } \\
\text { structured } \\
\text { process for in- } \\
\text { house } \\
\text { training }\end{array}$ & $\begin{array}{l}\text { Dedicated } \\
\text { team initially }\end{array}$ & $\begin{array}{l}\text { Cancer } \\
\text { centre }\end{array}$ \\
\hline D & 2 years & $\begin{array}{l}\text { Foundation } \\
\text { doctors and } \\
\text { surgical } \\
\text { trainees }\end{array}$ & $\begin{array}{l}\text { In-house } \\
\text { training }\end{array}$ & $\begin{array}{l}\text { Dedicated } \\
\text { team }\end{array}$ & DGH \\
\hline
\end{tabular}


Legend: RAS = Robot-Assisted Surgery; ODP= Operating Department Practitioner; DGH $=$ District General hospital

Overall, 32 operations were observed, of which 21 were robot-assisted. Of the 32 operations, 22 were rectal cancer resections (16 robot-assisted and six laparoscopic), with the other 10 representing a range of colorectal operations (five robot-assisted). This constituted 244 hours of data collection. Detailed field notes were written of what happened before, during, and after each operation, and these were written up as soon as possible after the operation. Nine of the rectal cancer resections were video recorded, eight robot-assisted and one laparoscopic, providing 52 hours of video data (Supplementary data, Table 2). Thirty post-operation interviews were undertaken (Supplementary data, Table 3). Interviews explored participants' perceptions of the operation and provided an opportunity to ask questions about aspects of the operation not immediately intelligible to an observer.

\section{Data analysis}

Throughout the study, an iterative approach to data collection and analysis was taken, to enable ongoing refinement and testing of the theories and the gathering of further data in light of such revisions. In Phase 2, a matrix display was produced for each theory being tested (Miles and Huberman, 1994). Each matrix display, with one operation per row, summarised the mechanisms anticipated by the theory (whether or not it was triggered), other mechanisms that appeared to be at play, contextual factors that were anticipated to trigger the mechanisms (whether or not they were present), other contextual factors that appeared to exert influence, and anticipated and unanticipated impacts. These provided a way of getting an overview of the data and keeping our analysis focused on theory testing. As we scrutinised the matrix displays, further questions became apparent, prompting a return to the field notes, interview transcripts, and video data for additional information. This involved indexing the data, using codes relevant to the questions and inductive codes to capture other aspects of the contexts, mechanisms, and impacts relevant to our theories. Analysis was conducted by two members of the study team and shared with the wider study team, including surgeons, an anaesthetist, and an ODP, to check for credibility.

\section{Research ethics}

Ethical approval for Phase 2 was granted by the National Research Ethics Service Committee Yorkshire \& The Humber - Leeds West (Ref: 13/YH/0153). Participating hospitals granted research governance approval. Phase 2 participants were provided with an information sheet and written consent was obtained.

\section{Findings}

Our Phase 2 observations indicated that introducing RAS led to a different division of labour compared to laparoscopic surgery. However, changes were not uniform and took on different configurations. The following fieldnote excerpt reveals the interaction 
between a surgeon with experience of RAS, a surgical assistant lacking experience in both colorectal surgery and RAS, and a scrub practitioner with experience of both:

The role of surgical assistant was taken on by a foundation doctor. At 11.10 a.m. the surgeon says to the scrub practitioner: 'Have some hem-oloks ready for me if necessary.' The robotic camera is dirty - the surgeon asks the surgical assistant to take it out. While still sat at the robotic console, the surgeon communicates with the surgical assistant to guide her in removing the camera and he tells the scrub practitioner to help her. The surgeon moves his head out of the console. The surgical assistant and the scrub practitioner clean the camera and put it back in again but the surgeon says it's still dirty, so they clean it again... The surgeon tells the surgical assistant to check with him if she's unsure about anything. The scrub practitioner explains to the surgical assistant how the suction works and then the surgical assistant provides suction. The surgeon asks the scrub practitioner to explain to the surgical assistant how the hem-o-lok works - she does... 11.55 a.m. The surgeon asks for a hem-o-lok for the surgical assistant to practice. The scrub practitioner gets a hem-o-lok and she and the circulating practitioner guide the surgical assistant on how to close it. Later in the operation the surgical assistant uses the hem-o-lok to ligate a vessel. With the guidance of the scrub practitioner, the surgical assistant also inserts and removes swabs. (Site D)

With the surgeon unscrubbed and at a distance, the surgical assistant and scrub practitioner work as a unit. This is in contrast to laparoscopic operations where the surgeon and surgical assistant work as a unit, the scrub practitioner supporting them. This level of collaboration between the surgical assistant and scrub practitioner was not observed in all robot-assisted operations. There was also variation across the robotassisted operations in the tasks the surgical assistant undertook. This variation in the ways in which the division of labour was reconfigured in RAS presents an analytic puzzle; how do particular configurations in the redistribution of work in response to RAS arise? What are the contextual factors that shape these new divisions of labour? And what are the consequences of these different configurations for teamwork and patient safety?

Our analysis revealed that it was the micro level factors of individual experience and team relationships that shaped the configuration of the division of labour in RAS.

\section{Individual experience}

\section{Experience of the surgical assistant}

The Phase 1 interviews found experience of the procedure was perceived by participants to be a key influence on division of labour within RAS (Alvarado et al., 2017). The surgical assistant's experience of the procedure seemed to be particularly important. Surgeons interviewed in Phase 1 reported finding it harder to guide surgical assistants during RAS; the physical separation meant that 'you can tell but not show'. This points to the relevance of the distinctive embodied skills of the surgeon - skills that are difficult to describe formally and, thus, often characterised as 'tacit knowledge' (Polanyi, 1962). 
Prentice (2007) powerfully documents how surgical apprenticeships introduce trainees to these tacit and embodied practices through hands-on guidance and demonstration. Indeed, she notes that "verbal guidance is a last resort" (Prentice, 2007: 551).

In later work, Prentice (2013) describes the teaching of laparoscopic surgery as being more difficult than open surgery because the surgeon has less direct control over the surgical trainee's actions. Our observations revealed surgeons would still take over instruments during laparoscopic surgery if the surgical trainee struggled to follow their directions, an option not available to the surgeon in RAS. Such differences are significant, given that the surgeon has overall responsibility for the operation and has to ensure a careful balance of allowing surgical trainees to develop their skills under close supervision while limiting the risk of injury to the patient (Bosk, 2003; Prentice, 2013).

As a consequence of these challenges, surgeons felt that, in RAS, it was important to have an experienced surgical assistant. Phase 1 interviewees in some hospitals reported that, because of this emphasis on experience, the role of the surgical assistant was taken on in RAS by experienced theatre nurses and ODPs who had trained as first assistants, whereas in laparoscopic operations a surgical trainee would typically have assisted. Thus, in some instances, a lack of experience resulted in the role of surgical assistant being taken away from surgical trainees for those operations, what Strauss et al. (1964) refer to as 'task-stripping'.

On the basis of the Phase 1 interviews, we developed the following tentative theory for testing in Phase 2:

Knowledge gained through experience of RAS and/or the particular procedure (context) enables the surgical assistant to anticipate the surgeon's requests and react to events without prompting (mechanism), supporting coordination between the surgeon and surgical assistant and ensuring that the surgical assistant's actions are performed correctly and in a timely manner (outcome).

To begin to test this theory, in Phase 2 we compared the tasks undertaken by surgical assistants during laparoscopic surgery and RAS and explored how this varied according to their level of experience. In laparoscopic operations, the surgical assistant held the laparoscopic camera and, to assist with retraction, a grasper. There were no changes in the instruments held by the surgical assistant and the surgeon's requests related to movement of the camera or grasper. However, if the surgical assistant was a surgical trainee or foundation doctor, the operation took on a teaching element and the extent of their involvement in the operation varied according to their level of experience. More experienced surgical trainees would frequently swap roles with the surgeon, the surgical trainee assisting the surgeon for the more difficult parts of the operation and then for other parts the surgical trainee would operate, guided by the surgeon, while the surgeon controlled the laparoscopic camera and assisted with retraction.

In robot-assisted operations, there was not the same opportunity for the surgeon and surgical trainee to swap roles (see also Beane, In press). The surgeon controlled the 
camera and, if using a four-arm robot, the surgeon would typically use two arms for retraction (with the camera held by one arm and scissors held in the remaining instrument arm). Some tasks that the surgical assistants were observed performing in RAS were the same as those undertaken by the operating surgeon in laparoscopic surgery, such as providing suction, inserting and removing swabs to absorb blood, and applying clips to a vessel. For such tasks, it could be anticipated that if a surgical assistant is experienced in laparoscopic surgery, in terms of having operated under the surgeon's guidance for parts of the procedure, they will have the necessary skills to undertake that task within a robotassisted operation. However, what we observed was surgical assistants offering or seeking permission to undertake the task, rather than going ahead and undertaking it autonomously, without seeking permission from the surgeon:

Trainee: 'Do you want some suction on that left side?'

Surgeon: 'Yeah.' (Site C)

Trainee: 'Shall I suck that tonsil swab?' (Site D)

This was also the case with retraction, despite this being a task that experienced surgical assistants undertake unprompted in laparoscopic surgery. While some surgeons talked about surgical assistants still being on the learning curve, so they were still learning what assistance to provide, it also seemed the surgeons were still learning what they could manage on their own and where they needed assistance, as revealed in the following instance:

Trainee: 'Would you like better traction from me or are you happy?'

Surgeon: 'I would but it seems like we're making some decent progress so I just want to wait.' (Site C)

Interviews undertaken in Phase 3 suggest it is only if and when surgeons establish more routinized ways of working with the robot in terms of what they undertake alone and where they require assistance that the surgical assistant could be expected to have knowledge of what assistance the surgeon is likely to want. For example, at Site A, Phase 3 interviewees agreed it is easy for the surgical assistant to know what assistance is required in robot-assisted prostatectomies because they are carried out in a routinized way:

Because we've always done prostatectomies, and both our surgeons are quite methodical, aren't they, that it will be the same thing every single time. So that's why we [the scrub practitioners] know exactly what we're doing, and they [the surgical trainees] know exactly what they're doing. (Site A, Urology ODP)

Such routinized ways of working with the robot mean a surgical assistant with experience of the procedure cannot only contribute to the safe, successful performance of the operation by carrying out tasks correctly but can do so without prompting, resulting in improved coordination with the surgeon and timely completion of those tasks. Thus, in addition to the individual tacit and embodied skills of surgical work discussed earlier, there are also tacit and embodied skills of collaboration in the OT. A number of scholars 
have noted the perceptual and manual skills required by team members to anticipate the actions of others and to provide timely and relevant support (Heath et al., 2018; Hindmarsh and Pilnick, 2002; Hindmarsh and Pilnick, 2007). Through experience, colleagues can be seen to develop the professional competence to recognise the relevance of particular bodily movements in relation to the local material environment and in the context of the procedure in play. These tacit, perceptual skills are extremely practical, as they enable colleagues to offer timely and appropriate assistance. However, to develop knowledge of surgical bodies in new situations, individuals need experience of those situations.

On the basis of these findings, we are able to make a number of refinements to our tentative theory and thus deepen our understanding of how practitioners' experience shapes the micro features of team co-ordination:

Knowledge gained through experience of the particular procedure (context 1) provides the surgical assistant with knowledge of what actions are likely to be required, which they make use of by making oral offers of assistance and/or preparing to act (mechanism 1). Where routinized ways of working with the robot have been established (context 2), the surgical assistant is able to anticipate the surgeon's requests and react to events without prompting (mechanism 2). Together, these behaviours support coordination between the surgeon and surgical assistant and increase the likelihood that the surgical assistant's actions are performed correctly and in a timely manner (outcome).

With regard to new tasks introduced by RAS, surgical assistants experienced in RAS were able to take on the tasks of changing and inserting robotic instruments. When the surgical assistant lacked this experience the scrub practitioner would typically take over these tasks, thereby impacting the division of labour between the surgical assistant and scrub practitioner.

However, there were other tasks introduced by RAS, resulting from the surgeon's position in the console, where the surgical assistant's experience of the procedure was significant. In the following quote the surgeon describes the need for the surgical assistant to communicate relevant information:

If there is anything which doesn't look right, I just need to see what is happening, and that is only possible by taking your eyes off the console and seeing what is happening. [...] If you have an experienced assistant then at least okay you don't need to take your eyes off but at least you can ask them, you can talk to them and they will communicate things back to you. (Site C, Surgeon)

In contrast, a less experienced surgical assistant would not be able to take on this task and instead, as the quote above suggests, the surgeon would retain responsibility for gathering the information needed. In Phase 1 interviews, the majority of surgeons considered their situation awareness was reduced during RAS, stating they are focused on a small area and therefore less aware of their environment; they have 'tunnel vision'. By answering the surgeon's questions, an experienced surgical assistant can contribute to the surgeon's situation awareness and, by reducing the need for the surgeon to come out of the console, 
distractions for the surgeon are reduced and the surgeon's concentration is increased. This in turn can contribute to patient safety, with better situation awareness of the surgeon being associated with fewer surgical errors (Catchpole et al., 2008; Mishra et al., 2008). It has also been argued that a reduction in distractions can have a positive impact on patient outcomes (Deutsch et al., 2012). Thus, a further extension to our theory regarding the role of experience is as follows:

Knowledge gained through experience of the particular procedure (context) enables the surgical assistant to respond to the surgeon's questions, allowing the surgeon to remain within the console (mechanism), increasing the surgeon's situation awareness and concentration (outcome).

\section{Scrub practitioner experience}

The experience of the scrub practitioner was not explicitly discussed in the Phase 1 interviews and therefore in Phase 2 we did not specifically seek to test any theory regarding the experience of the scrub practitioner. However, in Phase 2, we observed that, due to rotation of surgical trainees, when a surgical trainee was assisting, the scrub practitioner often had greater experience of RAS. In this situation, as noted above, scrub practitioners would take on the tasks introduced by RAS when working with a surgical assistant who lacked experience of RAS. Sometimes the surgeon explicitly asked the scrub practitioner rather than the surgical assistant to do these tasks, an example of 'taskproffering' (Strauss et al., 1963). In informal conversations during observations and in the post-operation interviews, scrub practitioners who had not trained to be first assistants described being uncertain about whether they should be changing robotic instruments, with inserting instruments into a patient being perceived as outside the scope of their role. Despite this, when asked to by the surgeon, all scrub practitioners did.

As indicated from the scenario with which we started the presentation of our findings, the assistance provided by the scrub practitioner when working with surgical assistants inexperienced in colorectal surgery went beyond those tasks introduced by RAS. Such guidance mainly related to how to use particular laparoscopic instruments, such as clip appliers. The scrub practitioner provided this guidance because the surgeon was not there at the patient side to be able to demonstrate. In doing so, the scrub practitioner contributed to the safe, successful performance of the operation by helping to ensure the tasks undertaken by the surgical assistant were completed correctly. Thus, a new theory emerged, summarised as:

Where the surgical assistant is inexperienced, in either RAS or the particular procedure, but the scrub practitioner is experienced in RAS (context), knowledge gained through experience enables the scrub practitioner to both guide the surgical assistant and undertake certain tasks on their behalf (mechanism), ensuring these actions are performed correctly (outcome). 


\section{Team relationships}

In addition to individual experience, we identified that working relationships between team members also shaped how the division of labour was reconfigured within RAS. As noted above, RAS leads to a fundamental change in the nature of teamwork in the OT, with the surgical assistant and scrub practitioner now working as a unit, in contrast to laparoscopic operations where it is the surgeon and surgical assistant working closely together, supported by the scrub practitioner. However, the extent to which the surgical assistant and scrub practitioner worked together as a unit varied across robot-assisted operations and appeared to be influenced by the working relationship between the surgeon and scrub practitioner. We observed some surgeons explicitly ask the scrub practitioner to support the surgical assistant, as illustrated in the scenario presented above. In doing this, the surgeon acknowledges the scrub practitioner's expertise and highlights this aspect of their role. Where this occurred, the willingness of the surgical assistant to accept support from the scrub practitioner increased, influencing the division of labour by enabling the scrub practitioner to take on this expanded role. However, Strauss et al. (1963) describe how attitudes regarding what constitutes an appropriate division of labour can vary not only between but also within professional groups and this was reflected in our findings, with attitudes towards the role of the scrub practitioner in RAS varying between sites. This suggests another contextual factor - the surgeon acknowledging this aspect of the scrub practitioner's role - to be added to the theory outlined above.

Team relationships also shaped the ways in which team members responded to the new tasks created by RAS. The surgeon's position in the console meant it became necessary for the surgical assistant and scrub practitioner to notify the surgeon of changes they may be unaware of. Members of the theatre team were conscious of the surgeon's reduced situation awareness and, in Phase 1 interviews, described it as their responsibility to act as the 'surgeon's eyes and ears'. This, in effect, created a new task for the theatre team in RAS. On the basis of the Phase 1 interviews, we developed the following tentative theory for testing in Phase 2:

Where the team are aware of the surgeon's reduced situation awareness (context), they communicate information to the surgeon to make them aware of changes they would otherwise be unaware of (mechanism), with the result that the surgeon's situation awareness is maintained, enabling them to adjust their decision/course of action based on this information, avoiding complications during the procedure (outcome).

However, our Phase 2 observations suggested that whether or not the surgical assistant and scrub practitioner carried out this task depended on their willingness to speak up and there was variation between sites in the extent to which the surgeon encouraged the surgical assistant and scrub practitioner to do so. Surgeons at Sites C and D repeatedly encouraged the surgical assistants and scrub practitioners to tell them what they were doing and to speak up if they were unsure. One surgeon at Site D said he did this partly to ensure they felt comfortable speaking up when necessary. A surgeon at Site $\mathrm{C}$ would ask the surgical assistant, at regular intervals throughout the operation and without reference 
to a particular task, how he or she was doing. Bosk (2003) found such communication to be common; he points to it as being a reminder to those in training that the consultant surgeon is legally responsible for their actions and is available to help, while also passing responsibility to the trainee for seeking help in situations beyond their level of competence. Another surgeon, at Site B, said he deliberately engaged in general conversation before an operation to encourage people to talk to him, demonstrating awareness of potential problems arising from staff feeling unable to speak up. Where the surgeon did not trust the surgical assistant and scrub practitioner to communicate necessary information, the surgeon came out of the console more frequently, retaining responsibility for maintaining an overall awareness of what was happening in the OT. The surgeon encouraging the surgical assistant and scrub practitioner to speak up so that they communicate necessary information is important for patient safety (Edmondson, 2003), enhancing the surgeon's situation awareness and resulting in reduced distraction and increased concentration for the surgeon by reducing the need for them to come out of the console. Thus, the revised theory is that:

Where the surgeon encourages the surgical assistant and scrub practitioner to speak up (context), they communicate information to the surgeon to make them aware of changes they would otherwise be unaware of (mechanism), with the result that the surgeon's situation awareness is maintained and their concentration is enhanced, enabling them to adjust their decision/course of action based on this information, avoiding complications during the procedure (outcome).

\section{Discussion and conclusions}

This paper provides the first empirical explanation of how the introduction of RAS changes the micro features of the division of labour in the OT. While others have explored how the introduction of new healthcare technologies can trigger shifts in the division of labour, the present study makes an important contribution to the literature by revealing how shifts triggered by the introduction of new technologies are mediated by micro level factors of the negotiation context: individual experience and team relationships. Drawing together the empirically tested theories presented in the findings, we propose the following overarching theory:

When working with a surgeon who acknowledges the scrub practitioner's expertise and encourages the surgical assistant and scrub practitioner to speak up and where there is an appropriate skill-mix between the surgical assistant and the scrub practitioner (context), their experience enables them to appropriately divide tasks between them and take on the new task of communicating information to the surgeon to make them aware of changes they would otherwise be unaware of (mechanism), ensuring that actions are performed correctly and the surgeon's situation awareness is maintained (outcome).

The analysis suggests experience of the procedure alone is not sufficient for a surgical assistant to engage as a competent practitioner in RAS. Where the surgical assistant lacks experience, the scrub practitioner's experience is an important resource for ensuring tasks are completed correctly, as they take on the role of guiding the surgical assistant. While 
previous research has pointed to the implications of RAS for training opportunities for surgical trainees (Beane, In press), this study reveals the training role experienced scrub practitioners may be requested by surgeons to take on. This represents a significant change in the responsibilities of the scrub practitioner. This change in responsibilities and working relationships is constrained to RAS and does not persist in operations that are not robot-assisted, even when the same team members are involved. With increasing use of RAS (Abrishami et al., 2014), this explanatory account provides guidance for theatre teams who have or are looking to introduce RAS.

The findings of our study have many parallels with previous studies of the division of labour in healthcare. For example, Goodwin et al. (2005) describe how, in the anaesthetic room, the undertaking of certain procedures by an ODP or an ODP instructing an anaesthetic trainee may be perceived as 'illegitimate participation' by some, regardless of the ODP's experience and knowledge, because it not only impinges on the rights of the anaesthetic trainee to develop the skills themselves but also jeopardises their identity, providing possible reasons as to why some surgical trainees in our study were reluctant to accept the scrub practitioner's support. Similarly, the finding that the surgeon's acknowledgement of the scrub practitioner's expertise increases the likelihood of the surgical trainee accepting their support fits with research that emphasises expertise as a social phenomenon that needs to be socially acknowledged (Carmel and BakerMcClearn, 2012). In line with Allen's (1997) and Liberati's (2017) findings regarding the blurring of the medical-nursing boundary, we saw theatre nurses and ODPs undertaking activities outside the scope of their role, although they were more uncomfortable with this boundary-blurring than previous studies suggest. While previous research has shown how nurses take on the work of doctors when doctors are absent (Allen, 1997), in RAS certain responsibilities fall to the scrub practitioner not because the surgeon is absent but because of the surgeon's physical and perceptual separation from the rest of the team.

A strength of this research is the combination of ethnographic, video, and interview data, enabling detailed analysis of how the division of labour is managed in practice as an ongoing social accomplishment. This responds to previous studies of the division of labour in healthcare that have emphasised the need for studies to observe practice, rather than to rely purely on interview data (Allen, 1997; Reeves et al., 2009; Svensson, 1996; Carmel and Baker-McClearn, 2012).

A further strength of our study is the use of a realist approach. Finn et al. (2010a), in their study of different models of teamwork and divisions of labour in genetic care, highlight the significance of human and social contextual factors such as strong previous working relationships and shared role and career expectations beyond traditional boundaries in supporting effective transformation of the division of labour, and argue that more detailed examination of the mechanisms through which these human and social contextual factors facilitate teamwork is required. The use of a realist approach in this study supported the identification of mechanisms through which different divisions of labour occurred and the contexts in which those mechanisms were triggered. In particular, taking a realist approach enabled us to understand the influence of micro level features of the negotiation 
context and to draw out some theoretically generalisable features about what works in what circumstances and how.

The theory of negotiated order identifies individual characteristics and interpersonal relationships as features of the negotiation context (Strauss et al., 1964; Strauss et al., 1963; Strauss, 1978). Allen (1997), drawing on negotiated order and boundary theory, shows how boundary-blurring is influenced by experience, which our analysis supports. However, other studies that draw on negotiated order and boundary theory have tended to focus on contextual factors at the organisational or ward level (Liberati, 2017; Svensson, 1996). Thus, this study makes an important contribution to the literature on the division of labour in healthcare by acting as a reminder of the importance of paying careful attention to micro level factors of the negotiation context. While contextual factors at the level of clinical area or ward, such as the typical level of patient acuity (Liberati, 2017), may not be amenable to change, our findings highlight individual behaviours, such as acknowledging aspects of a team member's role and encouraging team members to speak up, that can be promoted in order to foster a context where divisions of labour are reconfigured in ways that are beneficial for patient care.

\section{Acknowledgements}

We would like to thank the surgeons and theatre teams who generously gave up their time to participate in this study. We also thank Professor Carl Thompson for his comments on a draft of this article. We would also like to acknowledge the support of the NIHR Clinical Research Network.

\section{Funding statement}

This research was funded by the National Institute for Health Research (NIHR) Health Services and Delivery Research (HS\&DR) Programme (project number 12/5005/04). The views and opinions expressed therein are those of the authors and do not necessarily reflect those of the HS\&DR Programme, NIHR, NHS or the Department of Health.

\section{References}

Abbott A. (1988) The system of professions: an essay of the division of expert labour, Chicago: University of Chicago Press.

Abrishami P, Boer A and Horstman K. (2014) Understanding the adoption dynamics of medical innovations: Affordances of the da Vinci robot in the Netherlands. Social Science and Medicine 117: 125-133.

Allen D. (1997) The nursing-medical boundary: a negotiated order? Sociology of Health and IIIness 19: 498-520.

Alvarado N, Honey S, Greenhalgh J, et al. (2017) Eliciting Context-Mechanism-Outcome configurations: Experiences from a realist evaluation investigating the impact of robotic surgery on teamwork in the operating theatre. Evaluation 23: 444-462. 
Barley SR. (1986) Technology as an Occasion for Structuring: Evidence from Observations of CT Scanners and the Social Order of Radiology Departments. Administrative Science Quarterly 31: 78-108.

Barrett M, Oborn E, Orlikowski WJ, et al. (2012) Reconfiguring Boundary Relations: Robotic Innovations in Pharmacy Work. Organization Science 23: 1448-1466.

Beane M. (In press) Shadow Learning: Building Robotic Surgical Skill When Approved Means Fail. Administrative Science Quarterly 0: 0001839217751692.

Bezemer J, Cope A, Faiz O, et al. (2012) Participation of Surgical Residents in Operations: Challenging a Common Classification. World Journal of Surgery 36: 2011-2014.

Bezemer J, Cope A, Kress G, et al. (2014) Holding the Scalpel: Achieving Surgical Care in a Learning Environment. Journal of Contemporary Ethnography 43: 38-63.

Bezemer J, Murtagh G, Cope A, et al. (2011) "Scissors, Please": The Practical Accomplishment of Surgical Work in the Operating Theater. Symbolic Interaction 34: 398-414.

Bosk CL. (2003) Forgive and remember: Managing medical failure, Chicago: University of Chicago Press.

Carmel S and Baker-McClearn D. (2012) Expert nurses and the division of labour in hospitals. Health 16: 282-297.

Catchpole K, Mishra A, Handa A, et al. (2008) Teamwork and Error in the Operating Room: Analysis of Skills and Roles. Annals of Surgery 247: 699-706.

Dalkin S, Greenhalgh J, Jones D, et al. (2015) What's in a mechanism? Development of a key concept in realist evaluation. Implementation Science 10: 49.

Deutsch GB, Sathyanarayana SA, Gunabushanam V, et al. (2012) Robotic vs. laparoscopic colorectal surgery: an institutional experience. Surgical Endoscopy 26: 956-963.

Edmondson AC. (2003) Speaking Up in the Operating Room: How Team Leaders Promote Learning in Interdisciplinary Action Teams. Journal of Management Studies 40: 14191452.

Edmondson AC, Bohmer RM and Pisano GP. (2001) Disrupted Routines: Team Learning and New Technology Implementation in Hospitals. Administrative Science Quarterly 46: 685-716.

Finn R. (2008) The language of teamwork: Reproducing professional divisions in the operating theatre. Human Relations 61: 103-130.

Finn R, Currie G and Martin G. (2010a) Team Work in Context: Institutional Mediation in the Public-service Professional Bureaucracy. Organization Studies 31: 1069-1097.

Finn R, Learmonth M and Reedy P. (2010b) Some unintended effects of teamwork in healthcare. Social Science and Medicine 70: 1148-1154.

Fournier V. (2000) Boundary work and the (un)making of the professions. In: Malin N (ed) Professionalism, boundaries, and the workplace. London: Routledge, 67-86.

Goodwin D, Pope C, Mort M, et al. (2005) Access, boundaries and their effects: legitimate participation in anaesthesia. Sociology of Health and IIIness 27: 855-871.

Greenberg CC, Regenbogen SE, Studdert DM, et al. (2007) Patterns of Communication Breakdowns Resulting in Injury to Surgical Patients. Journal of the American College of Surgeons 204: 533-540.

Greenhalgh T, Humphrey C, Hughes J, et al. (2009) How Do You Modernize a Health Service? A Realist Evaluation of Whole-Scale Transformation in London. Milbank Quarterly 87: 391416.

Håland E. (2012) Introducing the electronic patient record (EPR) in a hospital setting: boundary work and shifting constructions of professional identities. Sociology of Health and IIIness 34: 761-775. 
Hall PM and Spencer-Hall DA. (1982) The social conditions of the negotiated order. Urban Life 11: 328-349.

Heath C, Luff P, Sanchez-Svensson M, et al. (2018) Exchanging implements: the micromaterialities of multidisciplinary work in the operating theatre. Sociology of Health and Illness 40: 297-313.

Hindmarsh J and Pilnick A. (2002) The Tacit Order of Teamwork: Collaboration and Embodied Conduct in Anesthesia. Sociological Quarterly 43: 139-164.

Hindmarsh J and Pilnick A. (2007) Knowing Bodies at Work: Embodiment and Ephemeral Teamwork in Anaesthesia. Organization Studies 28: 1395-1416.

Hughes EC. (2008) The sociological eye, New Brunswick: Transaction Books.

Hull L, Arora S, Aggarwal R, et al. (2012) The Impact of Nontechnical Skills on Technical Performance in Surgery: A Systematic Review. Journal of the American College of Surgeons 214: 214-230.

Lai F and Entin E. (2005) Robotic Surgery and the Operating Room Team. Proceedings of the Human Factors and Ergonomics Society Annual Meeting 49: 1070-1073.

Liberati EG. (2017) Separating, replacing, intersecting: The influence of context on the construction of the medical-nursing boundary. Social Science and Medicine 172: 135143.

Maines DR. (1982) In search of mesostructure: Studies in the negotiated order. Urban life 11: 267-279.

Marchal B, van Belle S, van Olmen J, et al. (2012) Is realist evaluation keeping its promise? A review of published empirical studies in the field of health systems research. Evaluation 18: 192-212.

Miles MB and Huberman AM. (1994) Qualitative data analysis: an expanded sourcebook, Thousand Oaks, California: SAGE.

Mishra A, Catchpole K, Dale T, et al. (2008) The influence of non-technical performance on technical outcome in laparoscopic cholecystectomy. Surgical Endoscopy 22: 68-73.

Pawson R and Tilley N. (1997) Realistic Evaluation, London: SAGE Publications.

Polanyi M. (1962) Personal knowledge: Towards a post-critical philosophy, Chicago: University of Chicago Press

Prentice R. (2007) Drilling Surgeons. Science, Technology \& Human Values 32: 534-553.

Prentice R. (2013) Bodies in formation: An ethnography of anatomy and surgical education, Durham: Duke University Press.

Randell R, Greenhalgh J, Hindmarsh J, et al. (2014) Integration of robotic surgery into routine practice and impacts on communication, collaboration, and decision making: a realist process evaluation protocol. Implementation Science 9: 52.

Reeves S, Rice K, Conn LG, et al. (2009) Interprofessional interaction, negotiation and nonnegotiation on general internal medicine wards. Journal of Interprofessional Care 23: 633-645.

Riley R and Manias E. (2006) Governance in operating room nursing: Nurses' knowledge of individual surgeons. Social Science and Medicine 62: 1541-1551.

Riley R and Manias E. (2009) Gatekeeping practices of nurses in operating rooms. Social Science and Medicine 69: 215-222.

Sanchez Svensson M, Heath C and Luff P. (2007) Instrumental action: the timely exchange of implements during surgical operations. In: Bannon L, Wagner I, Gutwin C, et al. (eds) ECSCW'07: Proceedings of the Tenth European Conference on Computer Supported Cooperative Work. Limerick, Ireland: Springer, 41-60. 
Serra H. (2010) Medical technocracies in liver transplantation: Drawing boundaries in medical practices. Health 14: 162-177.

Strauss A. (1978) Negotiations: Varieties, contexts, processes, and social order: Jossey-Bass Inc Pub.

Strauss A, Schatzman L, Bucher R, et al. (1964) Psychiatric ideologies and institutions, New York: Free Press.

Strauss A, Schatzman L, Ehrlich D, et al. (1963) The hospital and its negotiated order. In: Freidson E (ed) The hospital in modern society. New York: Free Press, 147-169.

Svensson R. (1996) The interplay between doctors and nurses-a negotiated order perspective. Sociology of Health and IIIness 18: 379-398.

Timmons S. (2011) Professionalization and its discontents. Health 15: 337-352.

Timmons S and Tanner J. (2004) A disputed occupational boundary: operating theatre nurses and Operating Department Practitioners. Sociology of Health and IIIness 26: 645-666.

Vincent C. (2010) How to improve patient safety in surgery. Journal of Health Services Research and Policy 15: 40-43. 